\title{
Prevalence of Micro Vascular Obstruction and Major Adverse Cardiac Events by Echocardiography in Patients with STEMI after Reperfusion Therapy Compared with CMR
}

\author{
ISLAM Sh. ABD EL-AZIZ, M.D. 1; ALI A. RAMZY, M.D. ${ }^{\text {; }}$ ALI A. EL-SHARKAWY, M.D. ${ }^{2}$; \\ MOHAMED F. ABD EL-MOATY, M.D. ${ }^{3}$ and MOHAMED A. HASSAN, M.Sc. 4 \\ The Department of Cardiology, Faculty of Medicine, Al-Azhar University ${ }^{1}$, National HeartInstitute ${ }^{2}$, \\ The Department of Radiology, Faculty of Medicine, Al-Azhar University 3 and The Department of Cardiology, \\ Zagazig General Hospital, Zagazig4, Egypt
}

\begin{abstract}
Background: Ischemic heart disease is nowadays the leading cause of morbidity and mortality in the western world. Accurate detection and evaluation of this disease are of major importance. Cardiac magnetic resonance imaging (CMR) has an increasing role in the detection and evaluation of ischemic heart disease, and can be used to measure global and regional myocardial function, the presence of ischemia and myocardial scar tissue.
\end{abstract}

Aim of Study: The primary aim of this study is to compare the CMR with the Echocardiography (Echo) in evaluating occurrence of micro vascular obstruction and major adverse cardiac events within one month of revascularization.

Material and Methods: The study was carried out at the National Heart Institutes during the period from 1 st of October 2016 till 1 st of October 2017. Twenty patients were included in the study with documented ST segment elevation myocardial infarction (STEMI) and underwent reperfusion with primary percutaneous coronary intervention (PCI).

All patients are subjected to history, laboratory investigation, Electrocardiogram (ECG), ECHO, revascularization by primary PCI, CMR and another Echo after revascularization.

Results: There was highly statistically significant relation between patients with Microvascular obstruction (MVO) and occurrence of major advance cardiac events (MACE) as all patients with MVO had MACE ( $p$-value $<0.001$ ), while only $6 \%$ of the patients without MVO had MACE. After revascularization, 4 patients had MVO (20\% of the study population), while MACE occurred in 5 patients (25\% of the study population). There were statistically significant relation between score index (SI) and Ejection Fraction (EF) before and after revascularization $(p$-value $<0.001)$ with mean score index before $1.27-\} 0.15$ and after $1.13-\} 0.09$ while mean EF before $52.80-\{5.55$ and after $57.80-\} 4.46$.

Correspondence to: Dr. Mohamed A. Hassan, E-Mail: Dr Mohamed Abdalla@outlook.com
After revascularization there were significant difference between score index by ECHO and that by CMR ( $p$-value= 0.035 ) while no significant difference measured between EF by ECHO and that by CMR.

Before revascularization only EF has significant correlation with MVO, patients without MVO had mean 54.25- 4.68 and patients with MVO had mean 47- $\{5.41$ with $p$-value $=0.029$ while no significant relation between score index, left ventricle end systolic diameter ( LVESD), and left ventricle end diastolic diameter (LVEDD) with MVO with $p$-value $>0.05$. As regarding occurrence of MVO and ECHO there were significant difference in score index between patients with MVO and patients without MVO ( $p$-value $<0.05)$ Also, EF has significant difference between patients with MVO and patients without MVO ( $p$-value <0.05).

After revascularization score index by ECHO has significant relation in prediction of MVO $(p$-value $=0.019)$. Also, score index by CMR has highly significant relation in prediction of MVO ( $p$-value $<0.001)$.

Conclusion: We conclude that data obtained by CMR are better than ECHO in assessment of MVO and MACE. Delay in revascularization by PCI after STEMI affect cardiac muscle and was associated with post revascularization chest pain, so we should start revascularization by primary PCI as soon as possible to protect cardiac muscle from infarction.

Key Words: STEMI-CMR-MVO-MACE-PCI.

\section{Introduction}

ISCHEMIC heart disease is nowadays the leading cause of morbidity and mortality in the western world. Accurate detection and evaluation of this disease are of major importance. Cardiac magnetic resonance imaging (CMR) has an increasing role in the detection and evaluation of ischemic heart disease [1] 
CMR can be used to measure global and regional myocardial function, the presence of ischemia and myocardial scar tissue. It is a noninvasive technique in which all these parameters can be acquired in one imaging session and has the advantage of using relatively safe contrast material without the use of radiation [2] .

A stress test is often indicated in symptomatic patients with typical or atypical chest pain or correlates suspected of being due to coronary artery disease (CAD) and who have a low or intermediate cardiovascular risk profile, as well as in asymptomatic patients with high cardiovascular risk profiles, such as diabetics, or in patients with known CAD during follow-up. Exercise electrocardiography is usually the first-level stress test, but this may not be appropriate for some patients (e.g., those with limited physical capacity) or nondiagnostic (e.g., due to not reaching the target heart rate). Therefore, stress tests that include noninvasive imaging are frequently used. Left ventricular wallmotion abnormalities induced by stress can be assessed both by using CMR and transthoracic echocardiography [3]

CMR provides cine movies of the heart, mostly based on steady-state free-precession acquisitions, with high blood-tissue contrast to allow for accurate cardiac chamber quantification and wall motion analysis both at rest and at stress [4]. It enables myocardial perfusion studies to detect myocardial ischemia and gives insights into the morphology of the myocardial tissue [5]

There are two main CMR techniques that highlight the strength of CMR to assess myocardial infarction. First, late gadolinium enhancement (LGE) imaging depicts irreversibly damaged myocardium that is present both acutely as necrosis, and chronically as fibrosis. It enables identification, verification and quantification of infarcted and scarred tissue, which can be used for the prediction of recovery of cardiac function after interventions or of patient outcome. Therefore, the speed and robustness of this technique is a great advantage that has promoted its widespread clinical application and acceptance [6]

Second, T2-weighted imaging allows the detection of myocardial edema, which is present in the acute stage of myocardial injury and represents the area that is compromised from ischemia. Even though this CMR technique still suffers from imperfect robustness, it has immense potential as it is currently the only noninvasive modality that allows the assessment of myocardial edema [7].

\section{Patients and Methods}

The study was conducted in National Heart Institutes during the period from 1 st of October 2016 till ${ }^{1 \text { st }}$ of October 2017.

This study included twenty patients with ST segment elevation myocardial infarction (STEMI). Patients with STEMI who were subjected to revascularization by percutaneous coronary intervention (PCI).

\section{The entire patient subjected to:}

\section{History taking:}

Careful history was taken from all included patients, stressing upon risk factors, the character, onset, and duration of chest pain, previous history of acute coronary syndrome, and the presence or absence of other co-morbid conditions also to obtain clinical data used for the diagnosis of coronary artery disease, hypertension (HTN), Smoking, socioeconomic status, Family history of CAD and diabetes mellitus (DM).

\section{Clinical examination:}

Thorough clinical examination (general and local examination) was performed for all studied patients, searching for signs of LV dysfunction, hemodynamic instability, and the presence or absence of associated cardiac or systemic diseases.

\section{Electrocardiography (ECG) analysis:}

A 12 lead ECG was performed upon presentation and repeated post PCI. The ECG was recorded at a paper speed of $25 \mathrm{~mm} / \mathrm{second}$ at calibration $1 \mathrm{mv}$ equals to $10 \mathrm{~mm}$.

\section{Laboratory investigation:}

All patients underwent laboratory investigations including:

Complete blood picture (CBC), renal function test, liver function test, troponin I, and viral hepatitis marker.

\section{Transthoracic Echocardiographic analysis:}

All patients underwent resting echocardiography before intervention (coronary angiography and PCI) and 3 days later. Using different views including para-sternal long and short axis views, apical 4 chamber views.

\section{With special stress on:}

1- Measurement of Ejection Fraction (by M-mode). 


\section{2- Assessment of wall motion abnormalities and score index:}

Segmental wall motion (SWM) was evaluated for akinesia, hypokinesia, or aneurysrn.

Left ventricular wall was divided into $17 \mathrm{seg}$ ments the wall motion of each segment was examined and scored according to the modification of the recommendation of the American Society of Echocardiography, [8] in which:

- Normal (defined as $5 \mathrm{~mm}$ or more of endocardial excursion and systolic wall thickening).

- Hypokinetic (defined as less than $5 \mathrm{~mm}$ of endocardial excursion and reduced thickening).

- Akinetic (defined as near absence of endocardial excursion or systolic thickening).

- Dyskinetic (defined as paradoxical excursion during systole).

SWM scoring index (sum of segment scores/ number of segments scored) was calculated, total (average of the 17 segments).

\section{Left ventricle dimensions:}

Left ventricle dimensions were measured by M-mode from parasternal Long axis view. These measurements include:

1- Left ventricular end diastolic diameter (LVEDD)

2- Left ventricular end systolic diameter (LVESD).

3- Posterior wall thickness (PWT).

4- inter ventricular septal thickness ( IVS)

5- Ejection fraction (EF)

\section{Coronary angiography:}

Coronary angiography was done using seldinger technique for femoral artery puncture and insertion of 6F sheath throw which 6F Judkin's left \& right diagnostic catheters were advanced over 0.035 guide wire to canulate the Left Main and Right coronary arteries followed by injection of radio contrast under fluoroscopy and cine with left anterior oblique (LAO) or right anterior oblique (RAO) caudal and cranial projection.

\section{Percutenoues Coronary Intervention (PCI):}

PCI was done to all patient with STEMI using guiding catheter to canulate the diseased coronary artery throw which 0.014 guide wire was advanced to cross the lesion positioned distally in the vessel. The stent was delivered to the site of lesion over the guide wire with proper positioning and deployment. All patients has TIMI flow III after PCI.
Angiographic coronary flow analysis [9]:

Coronary flow was graded according to dye TIMI study criteria as follows:

- TIMI grade 0: Complete occlusion, absent antegrade flow.

- TIMI grade I: Partial contrast penetration beyond an occlusion with incomplete distal filling

- TIMI grade II: Patent epicardial artery with opacification of the entire distal artery (however, contrast filling or washout is delayed)

- TIMI grade III: Patent epicardial artery with normal flow.

\section{Cardiac magnetic resonance imaging:}

Cardiac MRI will be done to all patients after 3 days of PCI to assess wall motion abnormality and micro vascular obstruction and its relation to major adverse cardiac events (heart failure, chest pain and cardiac death) as reported after one month follow-up. The infarcted myocardium appears hyperenhanced or "bright" compared with normal noninfarcted myocardium. This hyperenhanced region closely corresponds to the area of necrosis as measured by triphenyltetrazolium chloride staining [10]. A central hypoenhanced region within the hyperenhanced region corresponds to MVO.

\section{Follow-up}

All patients are followed-up for 1 month to determine the clinical state, chest pain, heart failure and cardiac death.

\section{Statistical Analysis:}

All data were collected, tabulated and statistically analyzed using SPSS 20.0 for windows (SPSS Inc., Chicago, IL, USA) \& MedCalc 13 for windows (MedCalc Software bvba, Ostend, Belgium). Continuous Quantitative variables e.g. age were expressed as the mean \pm SD \& median (range), and categorical qualitative variables were expressed as absolute frequencies (number) \& relative frequencies (percentage). Continuous data were checked for normality by using Shapiro Walk test. Mann-All tests were two sided. $p$-value $<0.05$ was considered statistically significant (S), $p$-value $<0.001$ was considered highly statistically significant (HS), and $p$-value $\geq 0.05$ was considered statistically insignificant (NS).

\section{Results}

The mean age of our study was 48.40 years \pm 10.17, ranging from 26 to 67 years. Most of our 
study populations were male (13 patients) representing $65 \%$ of study population and female $(7$ patients) representing $35 \%$ of the study population. The most prevalent risk factor was smoking affecting 12 patients (60\%), Diabetes Mellitus (DM) was the next affecting 8 patients $(40 \%)$, the third most common risk factor was Hypertention (HTN) affecting 6 patients (30\%), dyslipidemia 3 patients $(15 \%), 5$ patients $(25 \%)$ had positive family history of premature CAD as shown in Table (1). After revascularization all patients had TIMI flow III.

After revascularization 4 patients had MVO ( $20 \%$ of the study population) while MACE occurred in 5 patients ( $25 \%$ of the study population) as shown in Table (2).

There were statistically significant association between score index and EF before and after revascularization ( $p$-value $<0.001)$ with mean score index before $1.27 \pm 0.15$ and after $1.13 \pm 0.09$, while mean EF before was $52.80 \pm 5.55$ and after 57.80 \pm 4.46 . No statistically significant difference between LVESD and LVEDD before and after revascularization ( $p$-value $>0.05)$ with mean LVESD before $33.25 \pm 3.05 \mathrm{~mm}$ and after $33.90 \pm 2.22 \mathrm{~mm}$ and mean LVEDD before $52.40 \pm 3.08 \mathrm{~mm}$ and after $53.60 \pm 2.37 \mathrm{~mm}$ as shown in Table (3).

As regarding occurrence of $\mathrm{MVO}$ and $\mathrm{ECHO}$ there were significant difference in score index between patients with MVO and patients without MVO ( $p$-value $<0.05$ ). Also, EF had a significant difference between patients with MVO and patients without MVO $(p$-value $<0.05)$ as shown in Table (4).

Occurrence of MVO is not affected by post revascularization LVEDD or LVESD as no significant difference was present ( $p$-value $>0.05$ ) in patients with or without MVO as shown in Table (4).

As regard CMR and MVO there were significant difference in score index and $\mathrm{EF}$ between patients with MVO and patients without MVO ( $p$-value $<0.05)$ as shown in Table (5).

Also, after revascularization score index, EF, LVESD and LVEDD obtained by ECHO had no significant relation with occurrence of MACE ( $p$ value $>0.05$ ) as shown in Table (6).

In contrast with $\mathrm{ECHO}, \mathrm{CMR}$ has significant relation with MACE. There were significant differences between score index in patient without MACE and patients with MACE $(p$-value $<0.05)$.
Also, there were significant difference between $\mathrm{EF}$ in patients without MACE and patients with MACE ( $p$-value $<0.05$ ) as shown in Table (7).

Table (1): Distribution of major risk factors and demographic data.

\begin{tabular}{lcc}
\hline & Range & Mean \pm SD \\
\hline Age (years) & $26-67$ & $48.40 \pm 10.17$ \\
\cline { 1 - 2 } & No. & $\%$ \\
\hline Sex: & & \\
Male & 13 & 65 \\
Female & 7 & 35 \\
Smoking & 12 & 60 \\
DM & 8 & 40 \\
HTN & 6 & 30 \\
Dyslipidemia & 3 & 15 \\
FH & 5 & 25 \\
\hline
\end{tabular}

DM: Diabetes Mellitus. HTN: Hypertension.

FH : Family history for premature Coronary artery Disease.

Table (2): Outcome of the studied patients $(n=20)$.

\begin{tabular}{ccc}
\hline \multirow{2}{*}{ Outcome } & \multicolumn{2}{c}{$\begin{array}{c}\text { All studied patients } \\
(\mathrm{n}=20)\end{array}$} \\
\cline { 2 - 3 } & No. & $\%$ \\
\hline MVO: & & \\
Absent & 16 & 80 \\
Present & 4 & 20 \\
MACE & & \\
Absent & 15 & 75 \\
Present & 5 & 25 \\
\hline
\end{tabular}

MVO : Micro vascular obstruction.

MACE: Major advance cardiac events.

Table (3): Comparison between pre- and post-revascularization echocardiography among the studied patients $(\mathrm{n}=20)$.

\begin{tabular}{lllll}
\hline Parameters & $\begin{array}{c}\text { Pre- } \\
\text { Echo- } \\
\text { cardiography } \\
(\mathrm{n}=20)\end{array}$ & $\begin{array}{c}\text { Post- } \\
\text { Echo- } \\
\text { cardiography } \\
(\mathrm{n}=20)\end{array}$ & Test• & $\begin{array}{c}p \text {-value } \\
\text { (Sig.) }\end{array}$ \\
\hline $\begin{array}{l}\text { Score index: } \\
\text { Mean } \pm \text { SD }\end{array}$ & $1.27 \pm 0.15$ & $1.13 \pm 0.09$ & -3.697 & $<0.001$ \\
Median (Range) & $1.30(1-1.50)$ & $1.10(1-1.30)$ & $(\mathrm{HS})$
\end{tabular}

EF $(\%)$ :

$\begin{array}{lllll}\text { Mean } \pm \text { SD } & 52.80 \pm 5.55 & 57.80 \pm 4.46 & -3.835 & <0.001 \\ \text { Median (Range) } & 54.50(43-60) & 58(47-64) & & \text { (HS) }\end{array}$

$\operatorname{LVESD}(\mathrm{mm})$ :

Mean \pm SD $\quad 33.25 \pm 3.05 \quad 33.90 \pm 2.22 \quad-2.207 \quad 0.445$

Median (Range) 34 (28-38) 34 (30-37) (NS)

$\operatorname{LVEDD}(\mathrm{mm})$ :

Mean \pm SD $\quad 52.40 \pm 3.08 \quad 53.60 \pm 2.37 \quad-2.715 \quad 0.175$

Median (Range) 52.50 (47-57) 54 (50-57) (NS)

- Wilcoxon signed ranks test. $p<0.001$ is highly significant. 
Table (4): Comparison between patient with and without MVO regarding Post-Revascularization Echocardiography.

\begin{tabular}{lllll}
\hline $\begin{array}{l}\text { Post- } \\
\text { Revascularization } \\
\text { Echocardiography }\end{array}$ & $\begin{array}{c}\text { With MVO } \\
(\mathrm{n}=4)\end{array}$ & $\begin{array}{c}\text { Without MVO } \\
(\mathrm{n}=16)\end{array}$ & Test & $\begin{array}{c}p \text {-value } \\
(\mathrm{Sig} .)\end{array}$ \\
\hline $\begin{array}{l}\text { Score index: } \\
\text { Mean } \pm \mathrm{SD}\end{array}$ & $1.22 \pm 0.09$ & $1.10 \pm 0.08$ & -2.051 & 0.040 \\
$\quad$ Median (Range) & $1.25(1.10-1.30)$ & $1.10(1-1.30)$ & & $(\mathrm{S})$ \\
EF $(\%):$ & & & & \\
Mean \pm SD & $51.50 \pm 4.20$ & $59.38 \pm 2.92$ & -2.663 & 0.008 \\
Median (Range) & $51(47-57)$ & $59(55-64)$ & & $(\mathrm{S})$ \\
LVESD (mm): & & & & \\
Mean \pm SD & $33 \pm 2.94$ & $34.44 \pm 2.06$ & -0.859 & 0.391 \\
Median (Range) & $32.50(30-37)$ & $34.50(30-37)$ & & $(\mathrm{NS})$ \\
LVEDD (mm): & & & & \\
Mean \pm SD & $54.25 \pm 1.50$ & $53.44 \pm 2.55$ & -0.477 & 0.634 \\
Median (Range) & $55(52-57)$ & $53.50(50-57)$ & & $(\mathrm{NS})$ \\
\hline
\end{tabular}

- Mann Whitney U test. $\quad p<0.05$ is significant.

Sig.: Significance \& NS: Non significant.

Table (5): Comparison between patient with and without MVO regarding Post-Revascularization CMR.

\begin{tabular}{lllll}
\hline $\begin{array}{l}\text { Post- } \\
\text { Revascularization } \\
\text { MRC }\end{array}$ & $\begin{array}{c}\text { With MVO } \\
(\mathrm{n}=4)\end{array}$ & $\begin{array}{c}\text { Without MVO } \\
(\mathrm{n}=16)\end{array}$ & Test• & $\begin{array}{l}p \text {-value } \\
(\text { Sig. })\end{array}$ \\
\hline $\begin{array}{l}\text { Score index: } \\
\text { Mean } \pm \text { SD }\end{array}$ & $1.27 \pm 0.12$ & $1.05 \pm 0.08$ & -2.862 & 0.004 \\
$\quad$ Median (Range) & $1.30(1.10-1.40)$ & $1(1-1.30)$ & & $(\mathrm{S})$ \\
$E F(\%):$ & & & & \\
$\quad$ Mean \pm SD & $47.50 \pm 3.10$ & $61.88 \pm 4.11$ & -3.032 & 0.002 \\
Median (Range) & $46.50(45-52)$ & $62.50(55-68)$ & & $(\mathrm{S})$ \\
\hline
\end{tabular}

- Mann Whitney U test. $\quad p<0.05$ is significant. Sig.: Significance.

Table (6): Comparison between patient without and with MACE regarding Post-Revascularization Echocardiography.

\begin{tabular}{|c|c|c|c|c|}
\hline $\begin{array}{l}\text { Post- } \\
\text { Revascularization } \\
\text { Echocardiography }\end{array}$ & $\begin{array}{c}\text { With MACE } \\
(\mathrm{n}=5)\end{array}$ & $\begin{array}{l}\text { Without } \\
\text { MACE } \\
(\mathrm{n}=15)\end{array}$ & Test• & $\begin{array}{c}p \text {-value } \\
\text { (Sig.) }\end{array}$ \\
\hline \multicolumn{5}{|l|}{ Score index: } \\
\hline Mean \pm SD & $1.18 \pm 0.13$ & $1.11 \pm 0.08$ & -1.155 & 0.248 \\
\hline Median (Range) & $1.20(1-1.30)$ & $1.10(1-1.30)$ & & (NS) \\
\hline \multicolumn{5}{|l|}{$E F(\%):$} \\
\hline Mean \pm SD & $54 \pm 6.67$ & $59.07 \pm 2.73$ & -1.625 & 0.104 \\
\hline Median (Range) & $52(47-64)$ & $58(55-63)$ & & (NS) \\
\hline \multicolumn{5}{|l|}{ LVESD (mm): } \\
\hline Mean \pm SD & $33 \pm 2.55$ & $34.20 \pm 2.11$ & -1.057 & 0.290 \\
\hline Median (Range) & $33(30-37)$ & $35(30-37)$ & & (NS) \\
\hline \multicolumn{5}{|l|}{ LVEDD $(\mathrm{mm}):$} \\
\hline Mean \pm SD & $53.80 \pm 1.64$ & $53.53 \pm 2.61$ & -0.088 & 0.930 \\
\hline Median (Range) & $55(52-55)$ & $54(50-57)$ & & (NS) \\
\hline
\end{tabular}

- Mann Whitney U test. $p<0.05$ is significant \& NS: Non significant.
Table (7): Comparison between patient without and with MACE regarding Post-Revascularization CMR.

\begin{tabular}{lllll}
\hline $\begin{array}{l}\text { Post- } \\
\text { Revascularization } \\
\text { MRC }\end{array}$ & $\begin{array}{c}\text { With MVO } \\
(\mathrm{n}=4)\end{array}$ & $\begin{array}{c}\text { Without MVO } \\
(\mathrm{n}=16)\end{array}$ & Test• & $\begin{array}{c}p \text {-value } \\
\text { (Sig.) }\end{array}$ \\
\hline $\begin{array}{l}\text { Score index: } \\
\quad \text { Mean } \pm \text { SD }\end{array}$ & $1.22 \pm 0.16$ & $\begin{array}{l}1.05 \pm 0.09 \\
1(1-1.30)\end{array}$ & -2.212 & $\begin{array}{l}0.027 \\
(\mathrm{~S})\end{array}$ \\
$\quad \begin{array}{l}\text { Median (Range) } \\
1.30(1-1.40)\end{array}$ & & & \\
EF $(\%):$ & $51.60 \pm 9.55$ & $61.47 \pm 3.90$ & -1.969 & 0.049 \\
$\quad \begin{array}{l}\text { Mean } \pm \text { SD } \\
\text { Median (Range) }\end{array}$ & $47(45-68)$ & $62(55-67)$ & & $(\mathrm{S})$ \\
\hline
\end{tabular}

Mann Whitney U test. $p<0.05$ is significant. Sig.: Significance.

\section{Discussion}

Primary PCI is effective in securing and maintaining coronary artery patency and avoids some of the bleeding risks of fibrinolysis. Randomized clinical trials comparing timely primary PCI with in-hospital fibrinolytic therapy in high-volume, experienced centers have repeatedly shown that primary PCI is superior to hospital fibrinolysis [11].

Cardiac magnetic resonance imaging is newer imaging modalities that hold promise as alternative or supplementary imaging modalities for assessing patients who present with chest pain syndromes [12].

CMR has a unique ability to visualize important tissue features in patients with acute coronary artery syndrome. Perfusion magnetic resonance imaging using a first-pass technique, with fast injection of a gadolinium-based contrast agent, visualizes well-perfused myocardium as a hyper intense signal; myocardial edema shows as a bright signal on T2-weighted images, defining "myocardium at risk"; and delayed post-contrast sequences identify persistent MVO as a dark, hypo enhanced area in the context of white regions of late gadolinium enhancement (infarcted myocardium) [13]

In our study 20 patients were included. The study was carried out at National Heart Institutes during the period from 1 st of October 2016 till 1 st of October 2017. Twenty patients with documented STEMI and underwent reperfusion with primary PCI were included. ECHO and CMR were done after 3 days and patients were followed-up for one month to determine clinical state, chest pain, heart failure and cardiac death.

In our study we found that ECHO is an important diagnostic tool for the assessment of wall motion abnormalities, Ejection Fraction and valve lesion but some data are missed like edema, fibrosis and MVO. This is in agreement with Choi KM et al., [14] who found Echocardiography is an impor- 
tant imaging tool for the detection of (regional) wall motion abnormalities, especially in the acute phase; however, it is not able to give tissue-specific information such as edema or fibrosis owing to ischemic events.

These results are controversial with result by Li et al., [15] in their study. where fifty six patients with AMI with elective treatment by PCI were included, they found that the difference was of no statistical significance in the comparison of ECHO evaluation in LVEDD, LVESD, and LVEF prior to and following PCI. However, their study were in agreement with our result by $\mathrm{CMR}$, as we found by $\mathrm{CMR}$ there were significant difference in $\mathrm{EF}$ before and after revascularization.

Banerjee et al., [16] in another study reported that late PCI on persistent total occlusion 3-28 days after MI did not reduce rate of death reinfarction, heart failure and no change was observed in LVEF compared with optimal medical therapy, however we found improvement of LVEF after primary PCI and reduction of rate of death, heart failure.

Discrepancy between various studies may be from: Interval between MI and PCI, basic LVEF before PCI, global condition of the patients and degree of coronary artery stenosis. Improving of myocardial function including EF and diastolic function after revascularization may be due to improved perfusion at stunning area.

In another study made by Grothues F [17] found CMR is a good noninvasive diagnostic tool in ischemic heart disease, providing accurate, reproducible and well-validated measurements. CMR combines assessment of cardiac morphology, global and regional cardiac function, infarct size, MVO and area at risk in just one investigation.

CMR shows accurate regional wall motion abnormalities. In patients with AMI, wall motion abnormalities are the result of ischemia. First, the wall motion becomes hypokinetic; if the ischemia proceeds, it can become akinetic, which can then lead to the wall motion becoming dyskinetic [18]

These wall motion abnormalities are reversible if ischemia is resolved before necrosis develops. The recovery may take several days and in this period the myocardium is referred to as 'stunned'. The decreased regional wall thickening is directly related to the global function of the $\mathrm{LV}$, resulting in decreased LVEF. After 4-6 months of primary PCI, the LVEF will be increased in most cases owing to recovery of stunned myocardium [19], however in our study we found that LVEF is improved after primary PCI after 3 days by ECHO with highly significant difference $(p$-value $<0.001)$.

Although reperfusion has dramatically reduced mortality and morbidity in patients with ST-segment elevation myocardial infarction (STEMI), the benefits of primary coronary angioplasty are blunted by microvascular perfusion impairment, which prevents full recovery of distal flow. Microvascular obstruction commonly referred to as "no-reflow" or "low-reflow" regions probably relates to simultaneous necrosis of both capillary endothelial cells and myocytes in the core region of larger infarcts [20].

Patients with no-reflow more often had malignant arrhythmias, cardiac tamponade, and early congestive heart failure compared with patients without no-reflow. An explanation of those findings might have been the reduced end-diastolic wall thickness in MVO-positive segments, which might result in an increase in wall stress in the affected and adjacent segments [21]

In our study, the prevalence of MVO in patients successfully reperfused was $20 \%$. This number may be a little over or underestimated due to the small number of our sample, also natural selection may play a role because shocked or hemodynamically unstable patients were excluded from our study for patient safety.

In our study we found that MVO presence is associated with less improvement in LVEF than non-MVO group with significant difference $(p$ value 0.008 ). The impairment in the microcirculation leads to more myocardial cells damage which is non-regenerative leading to more impairment of the LV functions at follow-up. MVO volume assessed by CMR had negative correlation with LVEF.

Also we found that patients with low EF before revascularization have high susceptibility for occurrence of MVO like a study made by Lombardo et al., [22] found a lower mean LVEF in patients with MO compared with patients without MVO, in the initial cardiac MRI as well as in the followup.

Nijveldt et al., [23] describe myocardial segments exhibiting MVO are more likely to develop wall thinning and not regain function. MVO is a powerful predictor of global and regional functional recovery than the transmurality. 
We found strong positive relation between MVO and MACE which was assumed to MVO affect LV remodeling and its presence is associated with adverse outcome, like other study by Hombach et al., [24] who found Microvascular obstruction is a feature of acute myocardial damage encountered in up to $30 \%$ of patients with STEMI. The presence and extent of MVO after acute MI is associated with adverse LV remodeling and poor clinical outcome. Also it may attributed to decreased myocardial pump efficiency increasing the incidence of heart failure symptoms, and MVO may impair the distal microcirculation leading to thrombosis and increasing the incidence of MACE.

Baks et al., [21] demonstrated that the presence of MVO in dysfunctional myocardial segments was associated with significantly greater thinning of the myocardium compared with that in segments without MVO at follow-up. In contrast to segments without MVO, segments with MVO demonstrated no improvement in segmental wall thickening in a follow-up study at 5 months.

Also, we found that wall motion score after revascularization has strong significant correlation with the occurrence of MACE like study made by $\mathrm{Li}$, et al., [15] who found wall motion scores of the patients in the MACE group were significantly higher than the group without MACE.

In our study we found that MVO was present in patients even after reperfusion by primary PCI In compatible with study made by Matthijs et al., [25] found that MVO was present in patients with STEMI reperfused by primary PCI (even in patients with TIMI flow grade 3 post primary PCI. MVO and LVEF were predictors for MACE, with value added to clinical risk factors; also MVO was associated with cardiac death when adjusted for age and LVEF.

Hundley et al., [26] proves that cardiac MRI provides the assessment of function, perfusion, and tissue characterization in a highly reproducible manner during a single examination even in patients with acoustic window limitations. Cine MRI for evaluation of cardiac volumes, mass, and systolic function is considered a gold standard compared with other imaging modalities.

In addition to having predictive value for congestive heart failure, MVO seems to be an important predictor of cardiac death. Reasons for cardiac death in patients with MVO have been demonstrated by [27].
MVO is still the best predictor and probably indicates which patients should be investigated further. Screening for arrhythmias and progressive dilation, with follow-up echocardiography or CMR, could potentially identify a high risk for cardiac death [25].

To summarize the results of our study, MVO in patients with successful Primary PCI achieving TIMI-3 flow is fairly common. CMR-derived MVO is associated with a lower LVEF, increased ventricular volumes and infarct size, greater risk of MACE and predicts less improvement of LVEF after Primary PCI.

Although there is no doubt that epicardial obstruction can be followed by MVO, it is tempting to hypothesize that under certain circumstances, preexisting microcirculatory impairment may actually predispose to coronary artery occlusion. As proposed by Lerman et al., [28] microcirculatory alterations might be responsible for sluggish upstream flow, which in turn may make patients more vulnerable to intravascular thrombosis at the site of an unstable plaque.

Finally, we were trying to bring CMR closer to routine utilization; other issues in MVO assessment require further research. Indeed, before CMR is incorporated into guidelines, its role as a prognosticator must be confirmed in randomized trials prospectively investigating $\mathrm{MO}$, and with sufficient power to definitively ascertain the correlation between MO and future coronary events.

\section{References}

1- SOURIDES B., THEOFILOGIANNAKOS E., THEOFILOGIANNAKOS G., et al.: Clinical experience from 1000 consecutive cardiovascularMRI cases at a tertiary referral medical center. Hellenic. J. Cardiol., 48: 192197, 2007.

2- PAMBOUCAS C. and ROKAS S.: Clinical safety of cardiovascular magnetic resonance: Cardiovascular devices and contrast agents. Hellenic. J. Cardiol., 49: 352-356, 2008.

3- GIBBONS R.J., BALADY G.J., BRICKER J.T., et al.: ACC/AHA 2002 guideline update for exercise testing: summary article: A report of the American College of Cardiology/American Heart Association Task Force on Practice Guidelines Circulation, 106: 1883-1892, 2002.

4- CHAROENPANICHKIT C. and HUNDLEY W.G.: The 20 year evolution of dobutamine stress cardiovascular magnetic resonance. J. Cardiovasc. Magn. Reson, 12: 59, 2010.

5- GERBER B.L., RAMAN S.V., NAYAK K., et al.: Myocardial first-pass perfusion cardiovascular magnetic resonance: history, theory, and current state of the art. J. Cardiovasc. Magn. Reson, 10: 18, 2008. 
6- KIM H.W., FARZANEH-FAR A. and KIM R.J.: Cardiovascular magnetic resonance in patients with myocardial infarction: current and emerging applications. J. Am. Coll. Cardiol., 55: 1-16, 2009.

7- FRIEDRICH M.G.: Myocardial edema-a new clinical entity? Nat. Rev. Cardiol., 7: 292-296, 2010.

8- LANG R.M., BADANO L.P., MOR-AVI V., et al.: Recommendations for cardiac chamber quantification by echocardiography in adults: an update from the American Society of Echocardiography and the European Association of Cardiovascular Imaging. J. Am. Soc. Echocardiogr., 28: 1-39, 2015.

9- BEKKERS S.C., YAZDANI S.K., VIRMANI R., et al.: Microvascular obstruction: Underlying pathophysiology and clinical diagnosis. J. Am. Coll. Cardiol., 55: 16491660, 2010.

10-KIM R.J., FIENO D.S., PARRISH T.B., et al.: Relationship of MRI delayed contrast enhancement to irreversible injury, infarct age, and contractile function. Circulation, 100: 1992-2002, 1999.

11-ANDERSEN H.R., NIELSEN T.T., RASMUSSEN K., et al.: A comparison of coronary angioplasty with fibrinolytic therapy in acute myocardial infarction. N. Engl. J. Med. 349: 733-742, 2003.

12- BUDOFF M.J, ACHENBACH S., BLUMENTHAL R.S., et al.: Assessment of coronary artery disease by cardiac computed tomography: Circulation. Oct., 17, 114 (16): 1761-1791, 2006.

13-CHANG H., MIN J.K., RAO S.V., et al.: Non-ST-segment elevation acute coronary syn- dromes: Targeted imaging to re fi ne upstream risk strati fication. Circ. Cardiovasc Imaging, 5: 536-46, 2012.

14- Choi K.M., Kim R.J., Gubernikoff G., et al.: Transmural extent of acute myocardial infarction predicts long-term improvement in contractile function. Circulation, 104 (10): 1101-1107, 2001.

15-LI Y., LI C., JIN H., HUANG W., et al.: Magnetic resonance imaging in interventional therapy of patients with acute myocardial infarction prior to and after treatment. Exp. Ther. Med., 12: 1755-9, 2016.

16-BANERJEE P., BANERJEE T., KHAND A., et al.: Cleland JG.Diastolic heart failure: Neglected or misdiagnosed? J. Am. Coll. Cardiol., 39 (1): 138-41, 2002.

17- GROTHUES F., MOON J.C., BELLENGER N.G., et al.: Interstudy reproducibility of right ventricular volumes, function, and mass with cardiovascular magnetic resonance. Am. Heart J., 147 (2): 218-223, 2004.

18- CERQUEIRA M.D., WEISSMAN N.J., DILSIZIAN V., et al.: Standardized myocardial segmentation and nomen- clature for tomographic imaging of the heart: Circulation, 105 (4): 539-542, 2002.

19- ALETRAS A.H., TILAK G.S., NATANZON A., et al.: Retrospective determination of the area at risk for reperfused acute myocardial infarction with T2-weighted cardiac magnetic resonance imaging: Histopathological and displacement encoding with stimulated echoes (DENSE) functional validations. Circulation, 113 (15): 1865-1870, 2006.

20- AMBROSIO G., WEISMAN H.F., MANNISI J.A., et al.: Progressive impairment of regional myocardial perfusion after initial restoration of post ischemic blood flow. Circulation, 80: 1846-61, 1989.

21- BAKS T., VAN GEUNS R.J., BIAGINI E., et al.: Effects of primary angioplasty for acute myocardial infarction on early and late infarct size and left ventricular wall characteristics. J. Am. Coll. Cardiol., 47: 40-4, 2006.

22- LOMBARDO A., NICCOLI G., NATALE L., et al.: Impact of microvascular obstruction and infarct size on left ventricular remodeling in reperfused myocardial infarction: a contrast-enhanced cardiac magnetic resonance imaging study. Int. J. Cardiovasc Imaging, 28: 835-842, 2011.

23- NIJVELDT R., BEEK A.M., HIRSCH A., et al.: Functional recovery after acute myocardial infarction: Comparison between angiography, electrocardiography, and cardiovascular magnetic resonance measures of microvascular injury. J. Am. Coll. Cardiol., 52: 181-9, 2008.

24- HOMBACH V., GREBE O., MERKLE N., et al.: Sequelae of acute myocardial infarction regarding cardiac structure and function and their prognostic significance as assessed by magnetic resonance imaging. Eur. Heart J., 26: 54957, 2005.

25- VAN KRANENBURG M., MAGRO M., THIELE H., et al.: Prognostic value of microvascular obstruction and infarct size, as measured by CMR in STEMI patients. JACC Cardiovasc Imaging, 7: 930-939, 2014.

26- HUNDLEY W.G., BLUEMKE D.A., FINN J.P., et al.: Expert consensus document on cardiovascular magnetic resonance: A report of the American College of Cardiology Foundation Task Force on Expert Consensus Documents. J. Am. Coll. Cardiol., 55: 2614-62, 2010.

27- ITO H., MARUYAMA A., IWAKURA K., et al.: Clinical implications of the 'no reflow' phenomenon. A predictor of complications and left ventricular remodeling in reperfused anterior wall myocardial infarction. Circulation, 93: 223-8, 1996.

28- LERMAN A., HOLMES D.R., HERRMAN J., et al.: Microcirculatory dysfunction in ST-elevation myocardial infarction: Cause, consequence or both? Eur. Heart J., 28: 788-97, 2007. 


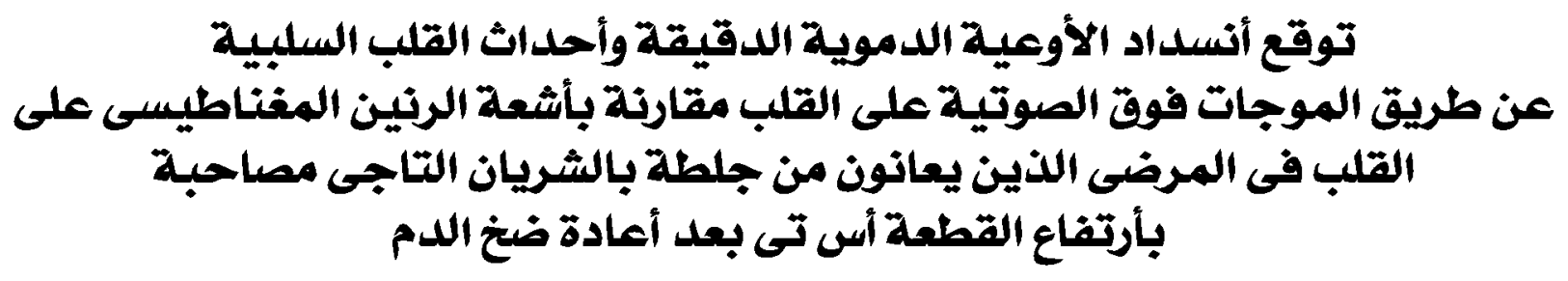

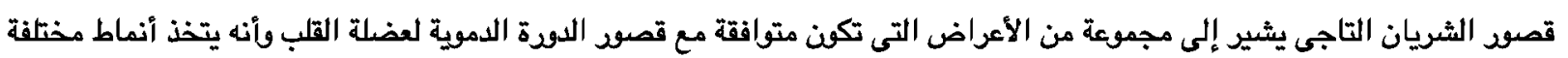

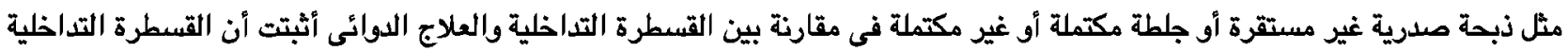

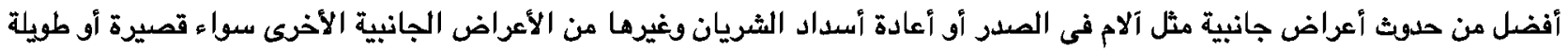

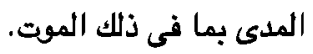

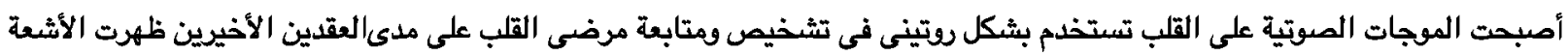

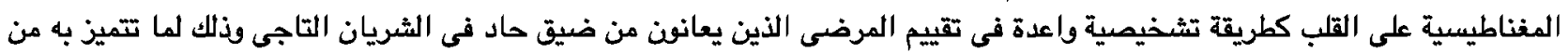

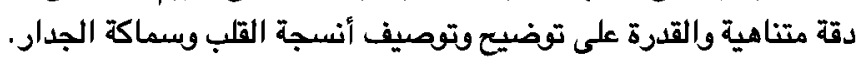

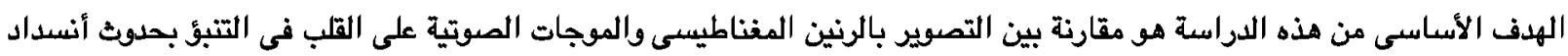

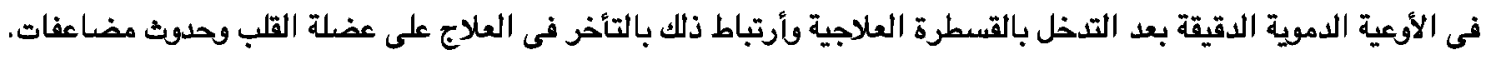

تم أدراج • rمريض مصابين بجلطة حادة فى الشريان التاجى فى الدراسة وتم علاجهم عن طريق القسطرةالتداخلية. وأجريت الدراسة

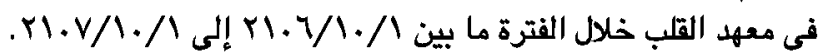

بعد عمل الدراسة وجدنا أن هناك علاقة بين وجود ضيق فى الأوعية الدموية الدقيقة بعد بالقسطرة العلاجية و حدوث آلام حادة فى الصدر وضعف عضلة القلب وأحتمالية الوفاة. وتم أستتتاج أن نتائج التصوير المغناطيسى على القلب أفضل من الموجات الصوتية على القلب من حيث التنبؤ بحدوث أنسداد في الأوعية

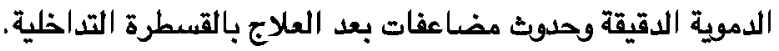

